\title{
Epidemiological Characteristics and Etiology of Budd-Chiari Syndrome in Upper Egypt
}

This article was published in the following Dove Press journal:

Journal of Blood Medicine

\author{
Muhamad R Abdel Hameed (ID) \\ Esam Abdel-Moneim Sadek \\ Elbeih' \\ Heba Mahmoud Abd El-Aziz ${ }^{2}$ \\ Ola Abdel-Haleem Afifi $^{3}$ \\ Lamiaa Mohammed Refaat \\ Khalaf \\ Mohammed Zakaria Ali Abu \\ Rahma iD ${ }^{5}$ \\ Abeer Sabry ${ }^{6}$ \\ 'Department of Internal Medicine \& \\ Hematology Unit, Assiut University \\ Hospitals and Bone Marrow \\ Transplantation Unit, South Egypt Cancer \\ Institute, Assiut University, Assiut, Egypt; \\ ${ }^{2}$ Department of Internal Medicine, Assiut \\ University Hospitals, Assiut University, \\ Assiut, Egypt; ${ }^{3}$ Department of Clinical \\ Pathology, Assiut University Hospitals, \\ Assiut University, Assiut, Egypt; \\ ${ }^{4}$ Department of Radiology, South Egypt \\ Cancer Institute, Assiut University, \\ Assiut, Egypt; ${ }^{5}$ Department of Tropical \\ Medicine and Gastroenterology, Assiut \\ University, Assiut, Egypt; ${ }^{6}$ Department of \\ Internal Medicine, Helwan University, \\ Helwan, Egypt
}

Correspondence: Muhamad R Abdel Hameed

Department of Internal Medicine \& Hematology Unit, Assiut University

Hospitals and Bone Marrow

Transplantation Unit, South Egypt Cancer Institute, Assiut University, Assiut, Egypt Tel $(+2) 01097510010$

Email dr.muhamadramadan@yahoo.com
Background and Objectives: Budd-Chiari syndrome (BCS) is a rare disorder caused by obstruction to hepatic venous outflow. It affects all races, usually during the third or fourth decade of life. Higher prevalence had being evident in developing countries. The aim of the present study was to clarify sociodemographic features, clinical, radiological presentations, and etiology of BCS among Upper Egyptian patients.

Patients and Methods: This retrospective cohort study enrolled 50 Upper Egyptian Patients with confirmed primary BCS. Liver, coagulation, and thrombophilia workup profiles were performed as anticardiolipin antibodies, lupus anticoagulant, protein $\mathrm{C}$, protein $\mathrm{S}$, and antithrombin III assays. Factor V Leiden and JAK2 mutations were assessed. Full radiological assessment was done.

Results: Fifty patients were included. There were 28 males (56\%) and 22 females (44\%) with mean age $(32.5 \pm 11.1$ years). The etiological factor was not identified in $22 \%$ of cases $(\mathrm{n}=11)$. Isolated factor $\mathrm{C}$ deficiency was found in $26 \%(\mathrm{n}=13)$ with male predominance $39.3 \%$ and protein $\mathrm{S}$ deficiency in $10 \%(\mathrm{n}=5)$. Factor $\mathrm{V}$ Leiden mutation was the etiology in 5 patients (10\%). Membranous web and antiphospholipid syndrome each were the etiology in $8 \%(n=4)$. Beh $̧$ et's disease was diagnosed in $4 \%(n=2)$. Cases of liver cirrhosis(LC) were $41 / 50(82 \%)$ they were $: 33 / 50(66 \%)$ LC child class C, $8 / 50(16 \%)$ LC child class B, and 0/50 ( $0 \%$ ) LC child class A. Abdominal pain was the most common symptom (96\%), and ascites was the most common sign (82\%). Obstruction of hepatic veins was present in $80 \%$.

Conclusion: BCS in Upper Egyptian patients was mainly occurred in males in the third and fourth decade of life, mostly with liver cirrhosis. The most common etiology is isolated protein $\mathrm{C}$ deficiency followed by Factor $\mathrm{V}$ Leiden mutation and isolated protein $\mathrm{S}$ deficiency. Hepatic veins obstruction was the most common pattern of vascular involvement.

Keywords: Budd-Chiari syndrome, Upper Egypt, factor V Leiden, thrombophilia, etiology, protein $\mathrm{C}$

\section{Introduction}

Budd-Chiari syndrome (BCS) was defined according to EASL guidelines as an obstruction of the hepatic venous outflow tract in absence of right-sided heart failure or constrictive pericarditis. ${ }^{1}$ Lesions causing BCS could be located in the small or large hepatic veins (HV) or in the suprahepatic part of inferior vena cava (IVC).

$\mathrm{BCS}$ is a rare disease, with the prevalence of 2 per 100,000 inhabitants and an annual incidence of approximately 0.2 cases per million. ${ }^{2}$ It has higher prevalence in developing countries such as China, India, Nepal, and South Africa. ${ }^{3}$

Budd-Chiari syndrome has four clinical variants; acute, subacute, chronic, and fulminant. The acute form is characterized by abdominal pain, ascites, and 
hepatomegaly, without evidence of portal hypertension. This form can be complicated by fulminant hepatitis. The chronic form is difficult to distinguish from cirrhosis regardless of the etiology. The subacute form is characterized by features of acute BCS with portal hypertension. It reflects an extension of a previous occurrence of thrombosis in the HV.

BCS can also be classified according to etiology either as primary or secondary. Primary BCS is often associated with the presence of thrombotic risk factors. While, secondary BCS could be caused by obstruction in hepatic veins outflow by surgical injury, extrinsic compression, or tumor infiltration. ${ }^{5}$ At least one hereditary or acquired pro-coagulative disorder is present in $74 \%$ of cases. As many as $30 \%$ of BCS patients carry a Factor V Leiden mutation (FVLM) and some showed the inherited deficiency of Protein C, S, and antithrombin III. ${ }^{2}$

India, Pakistan, Middle East, and Europe share many characteristics in terms of the level of obstruction and causal factors. However, in China, involvement of the IVC may be more common. ${ }^{6}$ The clinical differences among different areas can be explained by different causes and area-related prevalence, eg, oral contraceptives in Europe or extreme poverty in certain Asian countries and South Africa. ${ }^{5}$

In Egypt, there are few studies on the character of BCS and its etiology with lack of studies from Upper Egypt region. Thus, we aimed to study the sociodemographic features, clinical, radiological presentations of Budd-Chiari syndrome among Upper Egyptian patients and to identify the possible etiology in this group of patients.

\section{Patients and Methods}

The present retrospective cohort study enrolled 50 patients with confirmed diagnosis of primary BCS referred to Assiut University Hospital Internal, Medicine Department and Al-Rajhi Liver University Hospital as tertiary centers (Assiut, Egypt) from different Upper Egyptian cities, eg, Minia, Assiut, Sohag, Qena, Luxor and Aswan. An informed written consent for data collection was obtained from all subjects who participated in the study during follow up visits. A parent provides informed consent for any participants under the age of 18 years. The protocol of the study was approved by the ethical committee of Assiut University. Full history and clinical examination were recorded for all patients.
- Laboratory investigations included complete blood picture, liver profile, and coagulation screen which were assessed using Cell-Dyn Ruby (Abbot), Cobasintegra 800 plus and Sysmex CA-1500 (Siemens) respectively.

- To determine the etiology of BCS, investigations of thrombophilia were performed including:

Protein C global test was first performed, as a screening test for identifying the defects of protein $\mathrm{C}$ and $\mathrm{S}$ anticoagulant pathways, then followed by protein $\mathrm{C}$ and $\mathrm{S}$ assays. Antithrombin III and lupus anticoagulant assays were done. All coagulation tests were performed using auto-analyzer Sysmex CA-1500 and reagents supplied by Siemens (Marburg, Germany). In addition, anticardiolipin antibodies, antinuclear antibodies, and Factor $\mathrm{V}$ Leiden mutation were investigated. Janus kinas 2 (JAK2) mutational statuses were assessed by PCR exploring the possible presence of a myeloproliferative disorder.

Protein $\mathrm{C}$ global test is an activated partial thromboplastin (aPTT) time-based assay in which snake venom was used for activation of endogenous protein $\mathrm{C}$ and of the intrinsic coagulation cascade. The activated protein $\mathrm{C}$ in conjunction with endogenous protein $\mathrm{S}$ inactivated the procoagulatory cofactors VIII and Va. This delayed clot formation. The time taken for a clot to form was determined. In addition, before use in the test the sample was mixed $1+4$ with coagulation factor $\mathrm{V}$ deficient plasma. This minimized the influence of other factors and a reduced normalized ratio was then almost exclusively due to the presence of Factor $\mathrm{V}$ Leiden.

Protein $\mathrm{C}$ activity assay: Protein $\mathrm{C}$ in the patient sample was activated by a specific snake venom activator. The resulting activated protein $\mathrm{C}$ (protein $\mathrm{Ca}$ ) was assayed in a kinetic test by measuring the increase in absorbance at $405 \mathrm{~nm}$.

\section{Protein S Activity Assay}

Protein Ca proteolytically cleaves FVa which is generated during the activation of the coagulation cascade by Russel viper venom (RVV). In this reaction protein $\mathrm{S}$ acts as a cofactor which accelerates the reaction. As a result, the coagulation time increases proportionally to the activity of protein $\mathrm{S}$ in the sample. The addition of deficient plasma ensures that the test mixture has a sufficient supply of fibrinogen, Factor V, and the other necessary coagulation factors. 


\section{Antithrombin III (ATIII) Activity Assay}

The antithrombin III in the sample is converted by heparin into an immediate inhibitor and inactivates the thrombin present. The residual thrombin content is determined in a kinetic test measuring the increase in absorbance at 405 $\mathrm{nm}$ according to the following reaction:

ATIII sample+Thrombin excess (ATIII-Thrombin) + Thrombin residual

The absorbance change is inversely correlated to the antithrombin III activity in the sample.

\section{Lupus Anticoagulant (LA) Assay}

Russell's viper venom present in LA1 Screening Reagent initiates plasma clotting by directly activating factor $X$. LA antibodies prolong the LA1 Screening Reagent clotting time. LA2 Confirmation Reagent is similar to LA1Screening Reagent but with high phospholipid concentration. The extra phospholipid counteracts the LA antibody and largely corrects the clot time. DRVV test "bypass" factor VII of the extrinsic pathway and the contact and antihemophilic factor of the intrinsic pathway. Therefore, LA1Screening Reagent is more specific for LA than aPTT as they are not affected by contact factor abnormalities or by factor VIII deficiencies or antibodies.

\section{Anti-Cardiolipin IgM, IgG Assay}

The determination was based on an indirect enzyme linked immune reaction. The Alegria test strip was used with the diagnostic instrument Alegria - a fully automated random access analyzer (Orgentec Diagnostika, Germany).

\section{Antinuclear Antibodies Assay}

Antinuclear antibodies test is an indirect fluorescent antibody test that involves incubating dilutions of patient sera with a monolayer of fixed, permeabilized cells. Antibodies adherent to the cell monolayer were visualized with an anti-human immunoglobulin reagent that had been conjugated to a fluorescent tag. The reagents were provided by Diagnostic automation Inc. (CA, USA). The presence or absence of nuclear staining and the pattern of nuclear staining were identified by fluorescence microscopy.

DNA extraction for PCR: Genomic DNA was isolated from ethylene diaminetetraacetic acid (EDTA)-whole blood using QIAamp DNA Mini Kit (Qiagen, Germany) according to manufacturer's instructions.

\section{Detection of Factor $V$ Leiden (FVL)}

Genotyping by real-time PCR was performed using hydrolysis probes. Each genotyping primer/probe mix contained two labelled probes homologous to the two genotypes under investigation. The probes included one specific for the wild-type G1691allele (FAM-labeled) and the other specific for the mutant A1961 allele (VIC-labeled). The mixture was placed in a 96-well PCR plate using 7500 Fast Real-Time PCR system (Applied Biosystems, CA, USA). During qPCR amplification of the target DNA with 40 cycles of alternating temperature $\left(95^{\circ} \mathrm{C}\right.$ for 15 $\mathrm{s}$ and $60^{\circ} \mathrm{C}$ for $1 \mathrm{~min}$ ), the probes competed for binding across the variant region. The probe that was $100 \%$ homologous to the DNA binding site preferentially bonded and gave a fluorescent signal as PCR proceeded. Results were analyzed by the instrument software to indicate the presence of one of the following in each DNA sample: wild-type alleles only (normal), mutant alleles only (homozygous FVL), or both alleles (heterozygous FVL).

\section{JAK2 V6I7F Mutation Analysis}

Real-time quantitative polymerase chain reaction (RTPCR)-based allelic discrimination assay was used to detect the JAK2 V617F mutation employing TaqMan real-time technology and 7500 Fast Real-Time PCR system (Applied Biosystems, CA, USA). Extracted DNA (80 ng) from the patients was used to amplify the mutated and unmutated exon 14 of JAK2 in an allele-specific PCR. Genomic DNA amplification was done in a 40-cycle PCR at an annealing temperature at $61^{\circ} \mathrm{C}$. All reactions were carried out in a final volume of $25 \mu \mathrm{L}$ containing $1 \times$ PCR Master Mix (Applied Biosystems, USA), $900 \mathrm{nM}$ of both forward and reverse primers and $100 \mathrm{nM}$ of each probe. $^{7}$

The sequence of the forward and reverse primers was as follows:

(F5'AAGCTTTCTCACAAGCAAGCATTTGGTTT) and (R5'AGAAAGGCATTAGA AAGCCTGTAGTT) respectively. PCR products were separated by electrophoresis on a $3 \%$ agarose gel, stained with ethidium bromide, and viewed under UV light. A 203 base-pair fragment indicates the presence of the $1849 \mathrm{G}>\mathrm{T}$ mutation. A ratio of cycle threshold (Ct) between the Ct (JAK2 V617F) and Ct (JAK2 wild type) was calculated for each sample.

(JAK2 V617F $\geq 0.042$ ) indicates that JAK2 V617F mutation is detected, while (JAK2 V617F $<0.042$ ) indicates thatJAK2 V617F mutation is not detected. 
Radiological assessment using abdominal ultrasound and Duplex ultrasonography (US) was performed to assess the status of liver disease and patency of the hepatic veins (HVs), the portal vein, and the IVC. Abdominal multislice computed tomography (MSCT) and/or magnetic resonance imaging (MRI) and/or IVC venography were performed to confirm all diagnoses and to assess vascular anatomy. Patients with secondary BCS caused by intraluminal invasion by a parasite or a malignant tumor, or extraluminal compression by an abscess, cyst, or solid tumor were excluded.

\section{Statistical Analysis}

All data were analyzed using SPSS version 16. Results were presented as means and standard deviations (SD). Data were expressed as number and frequencies. The chisquared and $t$-test tests were used to test for differences among variables. $\mathrm{P}$ value less than 0.05 was considered significant; a $\mathrm{P}$ value less than 0.01 was highly significant (HS); and a $\mathrm{P}$ value less than 0.001 was very highly significant (VHS).

\section{Results}

Fifty Upper Egyptian patients were enrolled in the study. There were 28 males (56\%) and 22 females (44\%). Their age was between (13-57 years) with mean $(32.5 \pm 11.1)$. A total of 46 (92\%) patients showing chronic BCS while 4 $(8 \%)$ acute BCS presented with the classic triad of abdominal pain, hepatomegaly and ascites and were noncirrhotic as shown in Table 1 .

Table 2 summarizes the disease etiologies. More than one etiological factor were identified in $32 \%(n=16)$. The etiology was not identified in $22 \%$ of cases $(n=11)$. The first commonest etiology was isolated factor $\mathrm{C}$ deficiency in $26 \%(\mathrm{n}=13)$ followed by protein $\mathrm{S}$ deficiency in $10 \%$ $(\mathrm{n}=5)$ and Factor V Leiden mutation in $10 \%(\mathrm{n}=5)$ and membranous web in $8 \%(\mathrm{n}=4)$. Antiphospholipid syndrome diagnosed by positive lupus anticoagulant and anticardiolipin antibodies was present in $8 \%(n=4)$ also. History of hormonal therapy in the form of oral contraceptives in $6 \%$ of the females $(\mathrm{n}=3)$.

Behcet's disease was diagnosed in $4 \%(n=2)$ based on the diagnostic criteria of the International Study Group of Behçet's Disease. ${ }^{8}$

No patients had JAK2 mutation.

As regard the relation between the etiology and gender, there was a highly statistical significant difference with male predominance in both cases with isolated protein
Table I Baseline Sociodemographic and Laboratory Features of the Included Patients $(n=50)$

\begin{tabular}{|l|l|}
\hline M/F (n) & $\mathbf{2 8 / 2 2}$ \\
\hline $\begin{array}{l}\text { Distribution by age, n(\%) } \\
\quad<20 \text { yr }\end{array}$ & $5(10 \%)$ \\
$20-29$ & $15(30 \%)$ \\
$30-40$ & $19(38 \%)$ \\
$>40$ & $11(22 \%)$ \\
\hline Laboratory parameters & Mean \& Std. Deviation \\
\hline WBCs (xI0 $3 / \mathrm{L})$ & $5.7 \pm 1.7$ \\
Hb(g/dl) & $10.7 \pm 1.9$ \\
Platelets(×I03/L) & $164 \pm 53$ \\
Bilirubin (mg/dl) Total & $1.07 \pm 1.24$ \\
Direct bilirubin (mg/dl) & $0.57 \pm 0.89$ \\
ALT (U/L) & $41.47 \pm 5.37$ \\
AST (U/L) & $42.2 \pm 96.5$ \\
Albumin (g/dl) & $3.1 \pm 2.4$ \\
INR & $1.38 \pm 0.31$ \\
Creatinine (mg/dl) & $1.23 \pm 0.98$ \\
MELD score & $12.5 \pm 5.5$ \\
\hline Child Class (n= 50) & \\
Non cirrhotic n,(\%) & $9(18 \%)$ \\
Child class B n,(\%) & $8(16 \%)$ \\
Child class C n,(\%) & $33(66 \%)$ \\
\hline
\end{tabular}

Table 2 Etiology of Budd-ChiariSyndrome in the Studied Patients

\begin{tabular}{|l|l|}
\hline Etiology & $\mathbf{n}(\%)$ \\
\hline Isolated protein C deficiency & $\mathrm{I}(26)$ \\
No identified etiology & $\mathrm{II}(22)$ \\
Isolated protein S deficiency & $5(I 0)$ \\
Membranous web & $4(8)$ \\
Factor V Leiden mutation (Heterozygous) & $5(I 0)$ \\
Antiphospholipid Syndrome & $4(8)$ \\
Hormonal therapy(females) & $3(6)$ \\
Behçet's Disease & $2(4)$ \\
Combined protein C and S deficiency & $\mathrm{I}(2)$ \\
Combined protein C and S deficiency and antithrombin III & $\mathrm{I}(2)$ \\
Combined protein C and antithrombin III deficiency & $\mathrm{I}(2)$ \\
\hline
\end{tabular}

C deficiency $(\mathrm{P}=0.001)$ and others with unidentified etiology ( $\mathrm{P}=0.002)$ (Table 3$)$.

Most of the included patients, $82 \%$ had liver cirrhosis on admission $(n=41)$ while 9 patients have no liver cirrhosis. Child-Pugh classification among patients who had liver cirrhosis ( $\mathrm{n}=41), 33$ patients were Child class $\mathrm{C}(66 \%)$ while Child class B were in 8 patients (16\%) and no patients had Child class A. Mean MELD score was $12.5 \pm 5.5$. None of the included cases received anticoagulants (Table 1). 
Table 3 Relation Between Etiology and Gender

\begin{tabular}{|c|c|c|c|c|c|}
\hline Etiology & Males $\mathrm{n}(\%)$ & Females $\mathbf{n}(\%)$ & $\chi^{2}$ & $P$ value & Sig \\
\hline Isolated protein $\mathrm{C}$ deficiency & $\mathrm{II}(84.62)$ & $2(15.38)$ & 12.00 & 0.001 & VHS \\
\hline No identified etiology & $6(54.55)$ & $5(45.45)$ & 10.00 & 0.002 & VHS \\
\hline Isolated protein S deficiency & $0(0)$ & $5(100)$ & 5.00 & 0.025 & $S$ \\
\hline Membranous web & $4(100)$ & $0(0)$ & 4.00 & 0.046 & $S$ \\
\hline Factor $V$ Leiden mutation (Heterozygous) & $4(80)$ & $\mathrm{I}(20)$ & 4.00 & 0.046 & S \\
\hline Antiphospholipid syndrome & $0(0)$ & $4(100)$ & 4.00 & 0.046 & $S$ \\
\hline Hormonal therapy(females) & $0(0)$ & $3(100)$ & 3.00 & 0.083 & NS \\
\hline Beḩet's disease & $\mathrm{I}(50)$ & $I(50)$ & 0.00 & 1.000 & NS \\
\hline Combined protein $\mathrm{C}$ and $\mathrm{S}$ deficiency & $\mathrm{I}(100)$ & $0(0)$ & 1.00 & 0.317 & NS \\
\hline Combined protein $\mathrm{C}$ and $\mathrm{S}$ and antithrombin III deficiency & $\mathrm{I}(100)$ & $0(0)$ & 1.00 & 0.317 & NS \\
\hline Combined protein $C$ and antithrombin III deficiency & $0(0)$ & $\mathrm{I}(100)$ & 1.00 & 0.317 & NS \\
\hline
\end{tabular}

Abbreviations: NS, not significant; S, significant; VHS, very highly significant.

Abdominal pain was the most common symptoms in BCS patients (96\%), abdominal distension in 41 patients $(82 \%)$ as shown in Table 4.

The most common clinical signs were moderate to tense ascites (82\%), edema of lower limbs $(68 \%)$, and hepatomegaly (50\%) Table 4.

As shown in Table 5: most of the patients had obstruction at the level of hepatic veins with high statistical significance $(\mathrm{P}=0.000)=40(80 \%)$. Patients with protein c deficiency and those with unidentified etiology had obstruction at the level of hepatic vein with high statistical significance $\mathrm{p}$ values 0.001 and 0.002 , respectively. Five patients $(10 \%)$ had obstruction at both HV and IVC and 5 patients $(10 \%)$ had obstruction at the level of IVC. Isolated

Table 4 Clinical Presentations of Budd-Chiari Syndrome in the Studied Patients $(\mathrm{N}=50)$

\begin{tabular}{|l|l|}
\hline Symptoms & $\mathbf{n}(\%)$ \\
\hline Abdominal pain & $48(96)$ \\
Abdominal distension & $4 \mathrm{I}(82)$ \\
Hematemesis and/or melena & $18(36)$ \\
History of previous thrombosis & $5(I 0)$ \\
History of recurrent abortion & $3(6)$ \\
Recurrent oral and genital ulcer (Behget's disease) & $2(4)$ \\
\hline Signs & \\
Ascites & $4 I(82)$ \\
Lower limb oedema & $34(68)$ \\
Hepatomegaly & $25(50)$ \\
Splenomegaly & $2 I(42)$ \\
Dilated abdominal veins & $20(40)$ \\
Hepatic encephalopathy & $18(36)$ \\
Jaundice & $8(I 6)$ \\
Leg ulcers & $I(2)$ \\
\hline
\end{tabular}

protein $\mathrm{C}$ deficiency was the most common cause associated with H.V obstruction (Figure 1). All cases with factor V Leiden mutation had obstruction at the level of hepatic veins ( $p$ value 0.050 ) and all cases of membranous web were associated with IVC obstruction (Figure 2).

\section{Discussion}

Budd-Chiari syndrome is a rare disorder of the liver with heterogenous nature, characterized by obstruction of the hepatic venous outflow. ${ }^{9}$

Our current epidemiological study describes the sociodemographic features, etiology, and risk factors for BCS of 50 Upper Egyptian patients with confirmed diagnoses of primary BCS.

Previous studies found that BCS was usually occurring during the third or fourth decade of life, with slightly more common predominance in females. ${ }^{10}$ Another study in Egypt describing disease pattern in Delta region and Cairo found more females affection than males with $\mathrm{M} / \mathrm{F}$ ratio $43 / 57$ and mean patient age about 28 years, ${ }^{11}$ while our study showed that BCS is mainly occurring at middle age with the mean age about 32 years with male predominance: $M / F$ 28/22. AN Algerian study found that $M / F$ was $45 / 70$ and the mean age was 34 years. $^{4}$ However, A Chinese study by Lin found that patients with BCS had mean age of $(52.5 \pm 11.7)$ with $\mathrm{M} / \mathrm{F}$ ratio was $11 / 4 .^{12}$

Most of the patients in the current study were diagnosed during the chronic phase (92\%) of the disease; the rest of the patients were diagnosed during acute (8\%) stage. These results support other studies. ${ }^{13-16}$

In this study, Liver cirrhosis was noticed in $82 \%$ and most of them were Child class C (66\%) while $16 \%$ were Child class B and no cases with Child class A. Their 
Table 5 Distribution of the Site of Venous Obstruction as Detected by Radiological Assessment According to the Etiology of BuddChiari Syndrome

\begin{tabular}{|c|c|c|c|c|c|c|}
\hline Etiology & HV Only n(\%) & HV and IVC n(\%) & IVC Only n(\%) & $\chi^{2}$ & $P$ value & Sig \\
\hline Isolated Protein C deficiency & $13(100)$ & $0(0)$ & $0(0)$ & 14.00 & 0.001 & VHS \\
\hline Isolated protein S deficiency & $4(80)$ & $0(0)$ & $I(20)$ & 5.00 & 0.082 & NS \\
\hline Factor $\vee$ Leiden mutation & $5(100)$ & $0(0)$ & $0(0)$ & 6.00 & 0.050 & $\mathrm{~S}$ \\
\hline Antiphospholipid syndrome & $2(50)$ & $2(50)$ & $0(0)$ & 4.00 & 0.135 & NS \\
\hline Behcets disease & $0(0)$ & $2(100)$ & $0(0)$ & 3.00 & 0.083 & NS \\
\hline Non-identified etiology & $1 \mathrm{I}(100)$ & $0(0)$ & $0(0)$ & 12.00 & 0.002 & VHS \\
\hline Hormonal therapy & $2(66.67)$ & I(33.33) & 0 & 3.00 & 0.223 & NS \\
\hline Membranous web & $0(0)$ & $0(0)$ & $4(100)$ & 5.00 & 0.082 & NS \\
\hline Combined protein $\mathrm{C}$ and $\mathrm{S}$ deficiency & $\mathrm{I}(100)$ & $0(0)$ & $0(0)$ & 2.00 & 0.368 & NS \\
\hline Combined protein $\mathrm{C}$ and $\mathrm{S}$ and antithrombin III deficiency & $\mathrm{I}(100)$ & $0(0)$ & $0(0)$ & 2.00 & 0.368 & NS \\
\hline Combined protein $\mathrm{C}$ and antithrombin III deficiency & $\mathrm{I}(100)$ & $0(0)$ & $0(0)$ & 2.00 & 0.368 & NS \\
\hline Total (n\%) & $40(80)$ & $5(10)$ & $5(10)$ & 49.00 & 0.000 & VHS \\
\hline
\end{tabular}

Abbreviations: NS, not significant; S, significant; VHS, very highly significant.

presentation by symptoms and signs of portal hypertension and hepatic decompensation, explaining common symptoms of abdominal pain, distension, and upper GIT bleeding $96 \%, 82 \%$, and $36 \%$, respectively. While ascites, lower limb edema, and hepatomegaly were the most common presenting signs in $82 \%, 68 \%$, and $50 \%$, respectively.

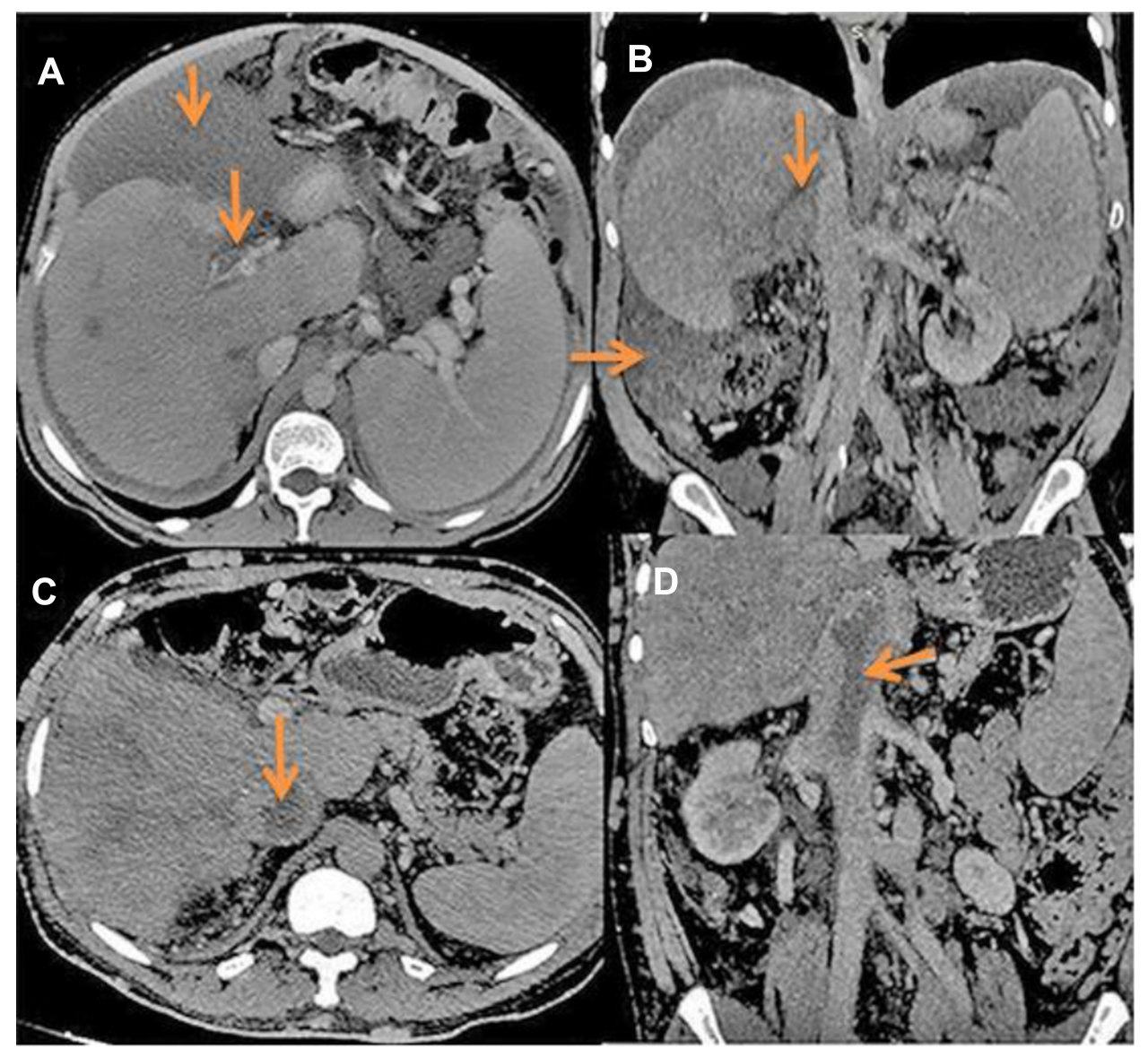

Figure I CT findings in BCS: (A) Axial CT image in a patient with acute BCS shows thrombosis of main portal vein seen as filling defect (arrow, A). Coronal CT image in another patient with acute BCS: shows filling defect in the middle HV (arrow, B). Ascites is also seen. Axial and coronal CT images in a patient with thrombosis of IVC seen as filling defect causing expansion of the lumen (arrows, $\mathbf{C}$ and D).

Abbreviations: BCS, Budd-Chiari syndrome; HV, hepatic veins; IVC, inferior vena cava. 

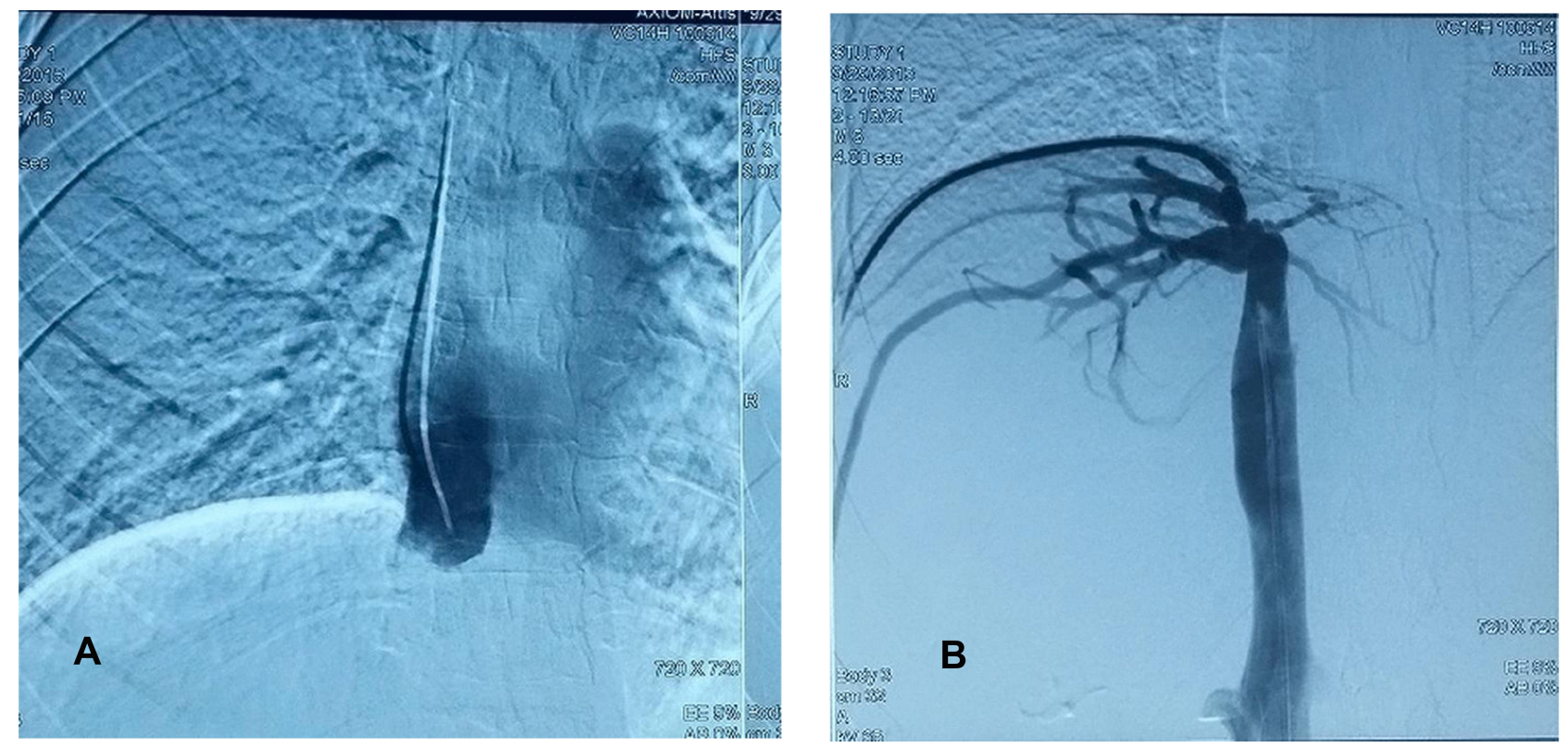

Figure 2 Trans-jugular (A) and trans-femoral (B) catheter venography of the IVC showing total occlusion of the suprahepatic portion of the IVC, with tight stenosis of its junction with the hepatic veins and multiple dilated collaterals.

Most of these patients were referred to our centers to be treated from the complications of liver cirrhosis after failure of catching definite diagnosis of cirrhosis.

Patients with BCS may show nonspecifically decreased levels of protein $\mathrm{C}$, protein $\mathrm{S}$, and antithrombin, attributable to impaired hepatic synthesis of these anticoagulants. ${ }^{17}$

In the current study isolated protein $\mathrm{C}$ deficiency was the most common identified etiology in $26 \%$ of patients while isolated protein $\mathrm{S}$ in $10 \%$ and no case with isolated antithrombin III. Similar to Afredj et al anticoagulant protein deficiency was observed in $28 \%$ of patients $(n=$ $18)$, dominated by protein $\mathrm{C}$ deficiency $(\mathrm{n}=13)$. Only 5 patients demonstrated a protein $\mathrm{S}$ deficiency, one had a mutation in the prothrombin gene and no patient demonstrated an antithrombin deficiency. ${ }^{4}$

Sakr et al 2011 identified deficiencies in antithrombin III, protein $\mathrm{C}$, and protein $\mathrm{S}$ in $43 \%, 43 \%$, and $1.1 \%$, of BCS patients, respectively. ${ }^{14}$ Similarly, Mohanty et al studied BCS patients in India and found deficiencies in antithrombin III, protein $\mathrm{C}$, and protein $\mathrm{S}$ in $3.8 \%$, $13.2 \%$, and $5.7 \%$ of patients, respectively. ${ }^{18}$ Uskudar and his colleagues in Turkey reported deficiencies in Antithrombin ш, Protein C, and Protein S in 3\%, 9\%, and $7 \%$ of BCS patients, respectively. ${ }^{19}$

In this study assessment for prothrombin gene mutation (PGM) was not done. Dutta et al study reported that there were no patients with BCS had PGM. ${ }^{13}$ G20210A PT gene mutation is a relatively uncommon prothrombotic risk factor with a weak prothrombotic risk. ${ }^{20}$

In Europe, factor $\mathrm{V}$ Leiden is a second prothrombotic factor and is found in $12-31 \%$ of BCS patients ${ }^{5,21}$ and antiphospholipid syndrome appears to be the third most common prothrombotic factor. ${ }^{22}$ Factor $\mathrm{V}$ Leiden induces resistance of activated factor $\mathrm{V}$ to degradation by activated protein C. ${ }^{23}$

In this study factor $\mathrm{V}$ Leiden mutation was present in $10 \%$. Both antiphospholipid syndrome and membranous web were detected in $8 \%$ of the patients. Behcet's disease was found in $4 \%$ similar to other studies which showed that $4-13 \%$ of BCS patients have Behcet's disease. ${ }^{14,19}$

In the current study, we found FVLM in 10\% of patients and all were heterozygous. Meanwhile, Sakr studied Egyptian BCS patients in Delta found that FVLM was the most common cause of disease $(53.1 \%$ of patients); 37.5\% of patients were FVLM heterozygotes, and $15.6 \%$ FVLM homozygotes. ${ }^{14}$ Another Egyptian study by Sakr and his colleagues observed that factor $\mathrm{V}$ Leiden mutation was present in $23 \%$ of patients. ${ }^{11}$

Similarly, a study in India by Mohanty et al found that FVLM was the most common etiology of BCS $(26 \%$ of patients). ${ }^{18}$ However, another Egyptian study showed that FVLM was the second most common mutation found in $48.6 \%$ of patients $(42.9 \%$ heterozygous and $5.7 \%$ homozygous). ${ }^{24}$ Nevertheless, observational studies did 
not find any Chinese BCS patients with either of the two FVLM mutations..$^{25,26}$

In this study hormonal therapy in the form of oral contraceptives was considered an etiological factor only in $6 \%$ of all BCS patients. This could explain the higher ratio of BCS found in males in our study compared to other Egyptian studies because of lower exposure to oral contraceptives among Upper Egyptian females than in Delta region females.

Exposure to oral contraceptives does not play a role as an etiology of BCS in the East. In both India and China, the use of oral contraceptives is less than $2 \%$, compared with $30 \%$ in Europe and above $40 \%$ in France. ${ }^{27,28}$ The current study showed that JAK2-V617F mutation was not detected in any case; thus, myeloproliferative disorder was not an identified etiology. Similar to Chinese study where the prevalence of the JAK2-V617F mutation appears to be particularly low. ${ }^{5}$

In the present study Most patients without identified etiologies had advanced liver disease and were child class $\mathrm{C}(\mathrm{n}=10)$ and more than one etiological factor were identified in $32 \%$ while other studies showing nearly $80 \%$ of BCS patients have at least one thrombotic risk factor, and $30-50 \%$ of them have two or more thrombotic risk factors. ${ }^{29,30}$ Uskudar and his colleagues in Turkey identified at least two etiological factors in $18.6 \%$ and three in $1.3 \%{ }^{13}$ Egyptian patients by Sakr and his colleagues identified at least one etiological factor in $48.9 \%$ of patients, two in $30.9 \%$, three in $8.5 \%$, and four in $3.2 \% .{ }^{14}$

The patterns of vascular involvement in BCS patients show variation between countries. IVC obstruction is prevalent in Asia, Nepal, South Africa, India, and China, whereas pure HVs obstruction predominates in Western countries. $^{31}$

This study showed that HVs obstruction was the most common pattern of venous obstruction $(80 \%)$, combined HVs and IVC obstruction was similar to isolated IVC obstruction and were observed in $10 \%$, while in another Egyptian study by Sakr et al, HVs obstruction, IVC obstruction, and combined HVs and IVC obstruction were found in $43 \%, 3 \%$, and $21 \%$ of patients, respectively. ${ }^{11}$

Darwish Murad reported isolated obstruction of HV, IVC, and both veins in $62 \%, 7 \%$, and $31 \%$ of patients, respectively. Behcet's disease was the main etiology associated with IVC obstruction in this study. ${ }^{32}$

Regarding the relation between the pattern of venous obstruction and the etiology, FVLM appears to be common in patients with IVC obstruction ${ }^{33}$ and the use of oral contraceptives, or pregnancy, is specifically associated with hepatic vein involvement. ${ }^{34}$

The present study showed that isolated protein C, protein $\mathrm{S}$ deficiency, and FVLM were associated with HVs obstruction. Meanwhile, membranous web was associated with IVC obstruction. Sakr et al reported protein S (48.8\%), protein C (41.9\%), antiphospholipid syndrome (32\%), and FVLM (20.9\%) were the most common causes of isolated hepatic veins thrombosis. ${ }^{11}$

\section{Conclusion}

BCS is a multifactorial disease in Upper Egyptian patients that occurs mainly in middle-aged males, mostly with chronic form. Isolated factor $\mathrm{C}$ deficiency was the most common etiology, while factor S deficiency and Factor $\mathrm{V}$ Leiden mutation were the second most common etiologies. Hepatic venous outflow was the main level of venous obstruction in our cohort. Identification of certain cause of BCS should not exclude searching for other etiological factors. Comparing our data with those of previous studies indicate that BCS of different geographic regions showing demographic difference.

\section{Ethics Approval and Consent to Participate}

This study was approved by the Regional Ethics Committee, Faculty of Medicine, Assuit University and was conducted in accordance with the provisions of the Declaration of Helsinki. Informed written consent was obtained from all participants before enrolment. A parent or legal guardian provided informed consent for any participants under the age of 18 years.

\section{Author Contributions}

E.A.S. conceived and designed the research. M.R.A., M.Z. A., A.M.M. and H.M.A. recruited patients, carried out the clinical investigations, collected clinical data and followed up the cases. O.A.A. and L.M.R. contributed in the interpretation of data for the work. M.R.A., M.Z.A., A.M.M., O.A.A. and L.MR prepared the original draft of the manuscript. All authors contributed to data analysis, drafting or revising the article, have agreed on the journal to which the article will be submitted, gave final approval of the version to be published, and agree to be accountable for all aspects of the work. 


\section{Disclosure}

The authors declare no conflicts of interest in this work.

\section{References}

1. EASL. Clinical practice guidelines. Vascular diseases of the liver. J Hepatol. 2016;64(1):179-202. doi:10.1016/j.jhep.2015.07.040

2. Valla DC. Primary Budd-Chiari syndrome. J Hepatol. 2009;50 (1):195-203. doi:10.1016/j.jhep.2008.10.007

3. Wang ZG, Jones RS. Budd-Chiari syndrome. Curr Probl Surg. 1996;33(2):83-211. doi:10.1016/S0011-3840(96)80001-3

4. Afredj N, Guessab N, Nani A, et al. Aetiological factors of Budd-Chiari syndrome in Algeria. World $J$ Hepatol. 2015;7 (6):903-909. doi:10.4254/wjh.v7.i6.903

5. Qi X, Han G, Guo X, et al. Review article: the aetiology of primary Budd-Chiari syndrome - differences between the West and China Aliment Pharmacol Ther. 2016;44(11-12):1152-1167. doi:10.1111/ apt. 13815

6. Valla D. Budd-Chiari syndrome/hepatic venous outflow tract obstruction. Hepatol Int. 2017;12(S1):168-180. doi:10.1007/s12072-0179810-5

7. Baxter EJ, Scott M, Campbell PJ, et al. Cancer genome project: acquired mutation of the tyrosine kinase JAK2 in human myeloproliferative disorders. Lancet. 2005;365(9464):1054-1061. doi:10.10 16/S0140-6736(05)71142-9

8. International Study Group for Behçet's Disease. Criteria for diagnosis of Behçet's disease. Lancet. 1990;335(8697):1078-1080.

9. Martens P, Nevens F. Budd-Chiari syndrome. United European Gastroenterol J. 2015;3(6):489-500. doi:10.1177/2050640615582293

10. Valla DC. Hepatic vein thrombosis (Budd-Chiari syndrome). Semin Liver Dis. 2002;22(1):5-14. doi:10.1055/s-2002-23202

11. Sakr MA, Abdelhakam SM, Dabbous HM, et al. Pattern of vascular involvement in egyptian patients with Budd-Chiari syndrome: relation to etiology and impact on clinical presentation epidemiological aspects of Budd-Chiari in Egyptian patients: a single-center study. Ann Hepatol. 2018;17(4):638-644. doi:10.5604/01.3001.0012.0933

12. Lin $\mathrm{M}$, Zhang F, Wang $\mathrm{Y}$, et al. Liver cirrhosis caused by chronic Budd-Chiari syndrome. Medicine. 2017;96(34):34. doi:10.1097/ MD.0000000000007425

13. Dutta AK, Chacko A, George B, Joseph JA, Nair SC, Mathews V. Risk factors of thrombosis in abdominal veins. World $J$ Gastroenterol. 2008;14(28):4518-4522. doi:10.3748/wjg.14.4518

14. Sakr M, Barakat E, Abdelhakam S, et al. Epidemiological aspects of Budd-Chiari in Egyptian patients: a single-center study. World J Gastroenterol. 2011;17(42):4704 4710. doi:10.3748/wjg.v17.i42.4704

15. Dilawari JB, Bambery P, Chawla Y, et al. Hepatic outflow obstruction (Budd-Chiari syndrome). Experience with 177 patients and a review of the literature. Medicine (Baltimore). 1994;73(1):21-36. doi:10.10 97/00005792-199401000-00003

16. Bayraktar UD, Seren S, Bayraktar Y. Hepatic venous outflow obstruction: three similar syndromes. World $J$ Gastroenterol. 2007;13(13):1912-1927. doi:10.3748/wjg.v13.i13.1912

17. Dayal S, Pati HP, Pande GK, Sharma MP, Saraya AK. Multilineage hemopoietic stem cell defects in Budd Chiari syndrome. J Hepatol. 1997;26(2):293-297. doi:10.1016/S0168-8278(97)80044-X

18. Mohanty D, Shetty S, Ghosh K, Pawar A, Abraham P. Hereditary thrombophilia as a cause of Budd-Chiari syndrome: a study from Western India. Hepatology. 2001;34(4):666-670. doi:10.1053/jhep. 2001.27948
19. Uskudar O, Akdogan M, Sasmaz N, Yilmaz S, Tola M, Sahin B. Etiology and portal vein thrombosis in Budd-Chiari syndrome. World J Gastroenterol. 2008;14(18):2858-2862. doi:10.3748/wjg.14.2858

20. Darwish MS, Plessier A, Hernandez-Guerra M, et al. Etiology, management, and outcome of the Budd-Chiari syndrome. Ann Intern Med. 2009;151(3):167-175. doi:10.7326/0003-4819-151-3-2009080 40-00004

21. Seijo S, Plessier A, Hoekstra J, et al. Good long-term outcome of Budd-Chiari syndrome with a step-wise management. Hepatology. 2013;57(5):1962-1968. doi:10.1002/hep.26306

22. Espinosa G, Font J, Garcia-Pagan JC, et al. Budd-Chiari syndrome secondary to antiphospholipid syndrome: clinical and immunologic characteristics of 43 patients. Medicine (Baltimore). 2001;80 (6):345-354. doi:10.1097/00005792-200111000-00001

23. Dahlbäck B, Hildebrand B. Inherited resistance to activated protein $\mathrm{C}$ is corrected by anticoagulant cofactor activity found to be a property of factor V. Proc Natl Acad Sci USA. 1994;91 (4):1396-1400. doi:10.1073/pnas.91.4.1396

24. El Sebay HM, Safan MA, Daoud AA, Tayel SI, Nouh MA, El Shafie S. Association of factor V Leiden, Janus kinase 2, prothrombin, and MTHFR mutations with primary Budd-Chiari syndrome in Egyptian patients. J Gastroenterol Hepatol. 2016;31(1):235-240. doi: $10.1111 /$ jgh. 13066

25. Qi X, Wu F, Ren W, et al. Thrombotic risk factors in Chinese Budd-Chiari syndrome patients. An observational study with a systematic review of the literature. Thromb Haemost. 2013;109 (05):878-884. doi:10.1160/TH12-10-0784

26. Wang H, Sun G, Zhang P, et al. JAK2 V617F mutation and 46/1 haplotype in Chinese Budd-Chiari syndrome patients. $J$ Gastroenterol Hepatol. 2014;29(1):208-214. doi:10.1111/jgh.12379

27. Li J, Temmerman M, Chen Q, Xu J, Hu L, Zhang WH. A review of contraceptive practices among married and unmarried women in China from 1982 to 2010. Eur J Contracept Reprod Health Care. 2013;18(3):148-158. doi:10.3109/13625187.2013.776673

28. Skouby SO. Contraceptive use and behavior in the 21st century: a comprehensive study across five European countries. Eur $J$ Contracept Reprod Health Care. 2010;15(Suppl 2):S42-S53. doi:10.3109/13625187.2010.533002

29. DeLeve LD, Valla DC, Garcia-Tsao G. Vascular disorders of the liver. Hepatology. 2009;49:1729-1764.

30. Senzolo M, Riggio O, Primignani M. Vascular disorders of the liver: recommendations from the Italian association for the study of the liver (AISF) ad hoc committee. Dig Liver Dis. 2011;43(7):503-514. doi:10.1016/j.dld.2010.11.006

31. Poddar P, Gurizala S, Rao S. Endovascular stenting of IVC using Brockenborough's needle in Budd-Chiari syndrome-a case report. Indian Heart J. 2014;66(3):363-365. doi:10.1016/j.ihj.2014.03.014

32. Darwish MS, Valla DC, de Groen PC, et al. Determinants of survival and the effect of portosystemic shunting in patients with Budd-Chiari syndrome. Hepatology. 2004;39(2):500-508. doi:10.1002/hep.20064

33. Deltenre P, Denninger MH, Hillaire S, et al. Factor V Leiden related Budd-Chiari syndrome. Gut. 2001;48(2):264-268. doi:10.1136/ gut.48.2.264

34. Valla DC. Hepatic venous outflow tract obstruction etiopathogenesis: Asia versus the West. J Gastroenterol Hepatol. 2004;19(s7):S204S211. doi:10.1111/j.1440-1746.2004.03642.x 


\section{Publish your work in this journal}

The Journal of Blood Medicine is an international, peer-reviewed, open access, online journal publishing laboratory, experimental and clinical aspects of all aspect pertaining to blood based medicine including but not limited to: Transfusion Medicine; Blood collection, Donor issues, Transmittable diseases, and Blood banking logistics; Immunohematology; Artificial and alternative blood based therapeutics; Hematology; Biotechnology/nanotechnology of blood related medicine; Legal aspects of blood medicine; Historical perspectives. The manuscript management system is completely online and includes a very quick and fair peer-review system. Visit http://www.dovepress.com/testimonials.php to read real quotes from published authors. 